\title{
Mecanismos moleculares do envelhecimento: revisão da literatura
}

\author{
Joana da Costa d'Avila*, Antonio Carlos Barbosa Ramos Junior ${ }^{\star *}$, Diane Ruth dos Santos Dourado***, \\ Rodrigo de Azeredo Siqueira ${ }^{\star * \star *}$, Aluana Santana Carlos ${ }^{\star \star \star *}$, Adalgiza Mafra Moreno ${ }^{\star \star \star * \star *}$
}

\section{Resumo}

O envelhecimento é um processo natural caracterizado pelo declínio progressivo da integridade fisiológica e da capacidade regenerativa do organismo. No envelhecimento patológico o declínio é acelerado e está frequentemente associado a um status pró-inflamatório sistêmico. Espécies reativas de oxigênio e outros radicais livres são produzidos naturalmente no metabolismo e durante a inflamação, porém em excesso causam estresse oxidativo e dano tecidual. Com o envelhecimento, o acúmulo de modificações oxidativas altera a estrutura e a função de biomoléculas e componentes celulares como membranas e organelas, tornando o organismo globalmente mais suscetível a agentes estressores e patológicos. Esta revisão vai focar na contribuição do estresse oxidativo para os diferentes mecanismos moleculares do envelhecimento. O envelhecimento é o principal fator de risco para o desenvolvimento de doenças crônico-degenerativas. Portanto, a compreensão de seus mecanismos moleculares contribuirá para o desenvolvimento de novas estratégias terapêuticas visando aumentar a qualidade de vida no envelhecimento.

Palavras-chave: Envelhecimento. Estresse oxidativo. Inflamação. Mecanismo molecular. Espécies reativas de oxigênio.

\section{Introdução}

A população mundial está envelhecendo em ritmo acelerado. De acordo com a Organização Mundial da Saúde (OMS), 1 em cada 5 pessoas terá 60 anos ou mais no ano de 2050 (WORLD HEALTH ORGANIZATION, 2015). O aumento da longevidade é resultado de avanços nos cuidados de saúde e no desenvolvimento socioeconômico que

* Farmacêutica. Doutora em Bioquímica pela Universidade Federal do Rio de Janeiro. Professora Associada da Faculdade de Medicina e Coordenadora do Laboratório de Pesquisa Pré-clínica da Universidade Iguaçu.

** Acadêmico do Curso de Medicina da Universidade Iguaçu.

*** $\quad$ Farmacêutica. Graduada em Farmácia pela Universidade do Grande Rio. Especialista em Farmácia Hospitalar pela Universidade Federal do Rio de Janeiro. Acadêmica do Curso de Medicina da Universidade Iguaçu.

***** Médico. Doutor em Endocrinologia pela Universidade Federal do Rio de Janeiro. Especialista pela Sociedade Brasileira de Endocrinologia e Metabologia. Professor Associado da Faculdade de Medicina da Universidade Iguaçu.

***** Bióloga. Doutora em Biologia pela Universidade do Estado do Rio de Janeiro. Professora Associada da Faculdade de Ciências Biológicas e da Saúde da Universidade Iguaçu.

${ }^{* * * * * *}$ Fisioterapeuta. Doutora em Ciências Cardiovasculares pela Universidade Federal Fluminense. Professora Associada da Faculdade de Ciências Biológicas e da Saúde e Coordenadora de Pesquisa da Universidade Iguaçu.

hhttp://dx.doi.org//10.5335/rbceh.v17i1.10543 
permitiram a diminuição da mortalidade infantil e o aumento da expectativa de vida (BEARD et al., 2016). Porém, o aumento da longevidade nem sempre é acompanhado de qualidade de vida. $\mathrm{O}$ envelhecimento é o maior fator de risco para o desenvolvimento de doenças crônico-degenerativas e com o aumento da longevidade, os idosos ficam doentes por mais tempo, geralmente lidando com várias doenças crônicas simultaneamente, o que gera impactos econômicos e sociais (GRUBER; HALLIWELL, 2017).

O funcionamento ideal de células, órgãos e sistemas depende de mecanismos de reparo e vigilância eficientes, detecção e depuração de biomoléculas e organelas defeituosas, e defesa contra patógenos e injúria tecidual. A falha dos mecanismos homeostáticos e o declínio cumulativo das reservas fisiológicas levam ao surgimento do quadro de fragilidade e eventualmente doenças degenerativas. A fragilidade é o resultado de uma desregulação sistêmica com diminuição da capacidade funcional e aumento da vulnerabilidade a agentes estressores (FEDARKO, 2011). O declínio funcional na fragilidade se dá em diferentes níveis: desde a dimensão orgânica, caracterizada por fraqueza, desnutrição, perda de peso e redução da atividade, até as dimensões psicológicas e sociais (Figura 1), que resultam em uma fragilidade cognitiva e contribuem para o isolamento e a morte do idoso (SACHA et al., 2017).

Figura 1: As múltiplas dimensões da fragilidade. Conceito multidimensional de fragilidade integrando vários domínios do funcionamento humano que, interagindo, podem acelerar o desenvolvimento da fragilidade

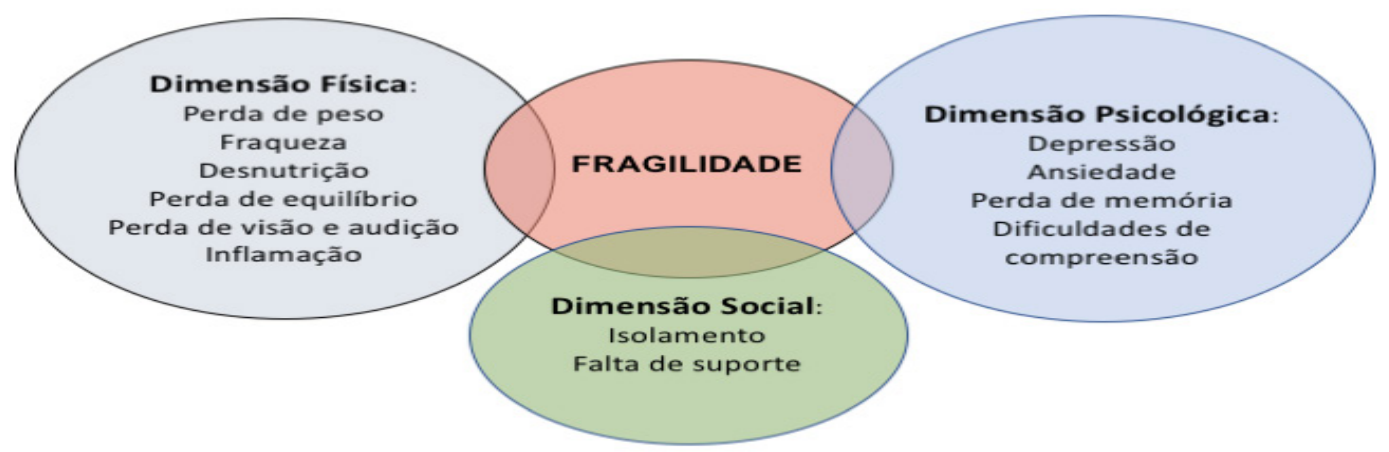

Adaptado de: Is It Time to Begin a Public Campaign Concerning Frailty and Pre-frailty? A Review Article (SACHA et al., 2017).

Curiosamente, indivíduos são extremamente heterogêneos no processo de envelhecimento, dependendo da herança genética e fatores ambientais, nutricionais, atividade física e abuso de substâncias. Diferentes manifestações do envelhecimento refletem variações na capacidade funcional ou na capacidade de células, tecidos e sistemas orgânicos de operarem de maneira ideal. As 
diferenças individuais de longevidade e suscetibilidade a doenças sugerem que componentes individuais podem ser modulados para retardar o início da fragilidade e o fim da vida (FÜLÖP et al., 2016). Já foi demonstrado que o envelhecimento de mamíferos pode ser desacelerado com abordagens genéticas, dietéticas e farmacológicas. No entanto, para traduzir esse conhecimento em terapias eficazes, é necessário entender melhor os mecanismos de senescência e como as reservas fisiológicas de um organismo podem ser aprimoradas.

Nas últimas décadas houve uma enorme expansão do conhecimento dos mecanismos moleculares e celulares da fisiologia e de doenças, o que impulsionou o campo da gerontologia, ou estudo das origens fisiológicas dos danos causadores do envelhecimento. Existem respostas compensatórias que tentam restabelecer a homeostase, e a interconexão entre os diferentes tipos de danos e respostas compensatórias têm sido alvos de intensa pesquisa por cientistas em todo o mundo. Diversos processos celulares, incluindo instabilidade genômica, desgaste de telômeros, alterações epigenéticas, perda de proteostase, defeitos em sensores de nutrientes, disfunção mitocondrial, exaustão de células-tronco, e comunicação intercelular alteradas são mecanismos comuns do envelhecimento em diferentes organismos (LÓPEZ-OTÍN et al., 2013). Aparentemente, todos os processos do envelhecimento convergem para falhas dos mecanismos homeostáticos e o acúmulo de danos moleculares e celulares, como causa fundamental do envelhecimento. Não existe um mecanismo predominante, e sim o conceito de que o envelhecimento é um processo multifatorial que envolve a interação de diversos mecanismos (Figura 2).

Figura 2: Mecanismos moleculares do envelhecimento. Os mecanismos moleculares do envelhecimento incluem danos a macromoléculas, desregulação metabólica, alterações epigenéticas, inflamação, defeitos na adaptação ao estresse, perda de proteostase e declínio da regeneração tecidual e da renovação de células tronco

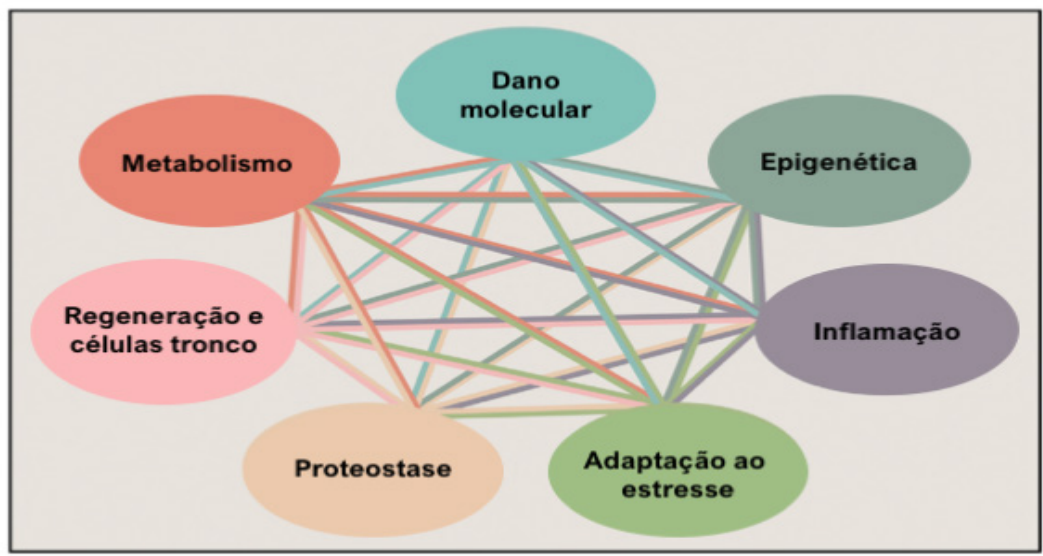

Adaptado de: Geroscience: Linking aging to chronic disease (KENNEDY et al., 2014). 
Os principais mecanismos moleculares do envelhecimento são representados de forma integrada (Figura 2), na qual não há um fator independente $\mathrm{e}$ preponderante que impulsiona o envelhecimento, mas uma rede de processos altamente interligados (KENNEDY et $a l ., 2014)$. O estresse oxidativo não representa um mecanismo, e sim um fator intrínseco e subjacente a todos os mecanismos moleculares do envelhecimento. Diversas teorias foram criadas para explicar o envelhecimento, desde o nível molecular, celular e sistêmico até teorias evolutivas. As teorias evolutivas buscam explicar a origem do envelhecimento e as diferenças da longevidade entre as espécies. Teorias sistêmicas consideram que a desregulação de sistemas fundamentais para o controle da homeostase (nervoso, imune e endócrino), estão relacionadas ao envelhecimento (WEINERT; TIMIRAS, 2003). Esta revisão vai focar nos mecanismos celulares e moleculares do envelhecimento, e na participação do estresse oxidativo nos diferentes mecanismos.

\section{Mecanismos moleculares do envelhecimento}

A teoria dos radicais livres foi criada por Harman em 1956, propondo que o envelhecimento seria resultado de danos teciduais cumulativos e acidentais gerados por radicais livres. A hipótese surgiu da observação de uma correlação inversa entre a taxa de consumo de oxigênio e a longevidade, e foi poste- riormente confirmado que quanto mais rápido o metabolismo de um organismo, menor a sua vida útil (SOHAL, 1986). Estas teorias direcionaram a atenção da pesquisa em envelhecimento para o metabolismo do oxigênio. Desde então, diversos estudos sugerem que a teoria dos radicais livres pode se relacionar com outras áreas da gerontologia (MULLER et al., 2007). Atualmente, inúmeras evidências demonstram que radicais livres são produzidos em sistemas biológicos e são capazes de oxidar biomoléculas, participando da fisiopatologia de diversas doenças e do próprio envelhecimento (BOVERIS; OSHINO; CHANCE, 1972; DRÖGE, 2002; HALLIWELL; GUTTERIDGE, 2015).

Radicais livres são espécies altamente reativas por possuírem elétrons desemparelhados em sua última camada eletrônica e, portanto, tendem a atingir a estabilidade doando ou removendo um elétron de biomoléculas adjacentes, como lipídeos, proteínas e ácidos nucleicos. Como o oxigênio possui alta afinidade por elétrons, tem alto poder oxidante, se reduzindo facilmente e formando espécies reativas de oxigênio (ERO). As EROs possuem átomos de oxigênio contendo pelo menos um elétron desemparelhado, por exemplo, o ânion superóxido $\left(\mathrm{O}_{2}^{-}\right)$ e o radical hidroxila $(\mathrm{OH} \bullet)$, ou ainda moléculas que não possuem elétrons desemparelhados, como o peróxido de hidrogênio $\left(\mathrm{H}_{2} \mathrm{O}_{2}\right)$, mas que ainda assim são capazes de reagir com metais de transição e gerar radicais livres altamente reativos (FORMAN, 2016; HALLIWELL; GUTTERIDGE, 2015). 
EROs e outros radicais livres são produzidos normalmente pelo metabolismo aeróbico e durante a inflamação, funcionando como moléculas de sinalização pleiotrópicas (SIES; JONES, 2020). Para evitar a injúria oxidativa e manter a homeostase, mitocôndrias, células e tecidos possuem diversos mecanismos antioxidantes que regulam o balanço redox e protegem o organismo da injuria oxidativa (FORMAN, 2016). Quando a produção de espécies reativas excede a capacidade antioxidante, o excesso de radicais livres oxida biomoléculas e componentes celulares, alterando sua estrutura e função, o que chamamos de estresse oxidativo. De fato, há inúmeras evidências demonstrando que, em altas concentrações, as EROs são prejudiciais aos organismos vivos, causando danos oxidativos a biomoléculas, organelas e membranas celulares, com forte associação à fisiopatologia de diversas doenças (HALLIWELL, 2001; LIGUORI et al., 2018).

As mitocôndrias são importantes fontes endógenas de EROs, pois durante a fosforilação oxidativa uma pequena fração do $\mathrm{O}_{2}$ é reduzida a superóxido $\left(\mathrm{O}_{2}^{-}\right)$ ao invés de água (BRATIC; LARSSON, 2013). De fato, foi mostrado que ocorre um acúmulo progressivo de dano oxidativo ao DNA mitocondrial com o envelhecimento (MECOCCI et al., 1993). Um dos mecanismos de defesa antioxidante mais importantes presentes na mitocôndria e no citoplasma das células é a enzima superóxido dismutase (SOD). Este é um sistema de defesa fundamental e altamente conservado entre espécies.
Estudos mostraram que a deficiência na expressão da SOD mitocondrial foi associada diminuição da longevidade em diferentes organismos (PAUL et al., 2007). A disfunção mitocondrial é um mecanismo de envelhecimento amplamente descrito e alguns autores consideram a mitocôndria o fator central de uma rede complexa de disfunções que eventualmente levam à senescência e morte celular (THEUREY; PIZZO, 2018).

\section{Alterações genômicas e epigenômicas}

Alterações na cromatina são cada vez mais reconhecidas como um importante mecanismo causador do envelhecimento celular. Essas alterações incluem aumento da instabilidade genômica e aumento do dano ao DNA (ácido desoxirribonucleico), desgaste de telômeros e alterações epigenéticas. A integridade genômica depende de mecanismos de reparo de danos ao DNA e do remodelamento da cromatina. Com o tempo, esses mecanismos perdem eficácia, causando a desestabilização do genoma relacionada ao envelhecimento (KEENAN; ALLAN, 2019). Quando os mecanismos de reparo falham, mas a célula sobrevive, podem ocorrer danos irreparáveis ao DNA. Uma célula que acumulou uma grande quantidade de dano ao DNA, ou uma que não conserta mais efetivamente os danos incorridos no DNA, pode entrar em um dos três estados possíveis: senescência (um estado irreversível de dormência); apoptose (morte celular programada); ou divisão celular descontrolada, que 
pode levar à formação de um tumor cancerígeno .

O dano ao DNA geralmente causa erros na síntese do DNA durante a replicação ou reparo; esses erros são uma importante fonte de mutação. Em contraste com os danos no DNA, a mutação é uma alteração na sequência de bases do DNA. Uma mutação não pode ser reconhecida e reparada por enzimas e portanto, pode ser replicada quando a célula se multiplica. Assim, o dano ao DNA de células que se dividem com frequência, por originar mutações, é uma causa proeminente de câncer. Por outro lado, o dano ao DNA em células que se dividem com pouca frequência é uma causa potencial de envelhecimento (BEST, 2009).

O dano à estrutura primária do DNA pode ser endógeno (por EROs) ou exógeno (por radiação, p.ex.) e resulta em quebras de fita simples ou da fita dupla, formação de adutos e ligações cruzadas das cadeias de DNA. Normalmente o dano é reconhecido por enzimas especializadas em reparar o DNA utilizando uma sequência não danificada na cadeia de DNA complementar ou em um cromossomo homólogo como molde. Para que as enzimas de reparo tenham acesso ao DNA há um relaxamento da cromatina no sítio onde houve o dano e a ação rápida de enzimas modificadoras de histonas como as sirtuínas (SIRT6), uma histona desacetilase dependente de nicotinamida adenina dinucleotídeo (NAD), e a poli-(ADP-ribose) polimerase 1 (PARP1), que também depende de NAD para sua atividade de ADP- -ribosilação de histonas, afrouxando a interação entre as histonas e o DNA e tornando o local do dano mais acessível para a atividade de reparo do DNA (RAY CHAUDHURI; NUSSENZWEIG, 2017). PARP1 está emergindo como um fator central na resposta geral ao estresse celular com funções em diversos de mecanismos moleculares, como remodelação da cromatina, transcrição, sinalização de danos ao DNA, reparo do DNA, regulação do ciclo celular, morte celular e inflamação. Há ampla evidência de que a PARP1 tem papéis diretos e indiretos nos mecanismos de envelhecimento e longevidade, o que o torna um interessante alvo na busca de mecanismos do processo de envelhecimento (MANGERICH; BÜRKLE, 2012). Curiosamente, manipulações de enzimas modificadoras de histonas como as sirtuínas e PARP-1 têm um claro potencial para combater doenças associadas à idade, como a síndrome metabólica, diabetes tipo 2 , doenças cardiovasculares e neurodegenerativas, câncer e o declínio funcional normal do envelhecimento (FERRARIS, 2010; SATOH; STEIN; IMAI, 2011; VAN DE VEN; SANTOS; HAIGIS, 2017).

Danos excessivos no DNA ou reparo insuficiente do DNA favorecem o processo de envelhecimento, causado pelo acúmulo de mutações. Estudos de monitoramento das mutações genéticas demonstraram níveis significativos de mutações nos tecidos envelhecidos. Células envelhecidas exibem um aumento nas mutações no DNA mitocondrial e um declínio na função mitocondrial (PINTO; MORAES, 2015; WEI et al., 
1998). Certos genes acumulam mais erros com o tempo, e algumas regiões do genoma, como os telômeros, apresentam maior quantidade de mutações pontuais (BLASCO, 2007).

Os telômeros são sequências de DNA não codificantes localizadas nas extremidades dos cromossomos que protegem $o$ material genético e a cromatina de desgastes no processo de replicação. A cada ciclo de replicação e divisão celular ocorre uma perda de pequena quantidade de DNA em cada extremidade do cromossomo, resultando em um encurtamento dos telômeros. Diferentemente das células somáticas, as células germinativas e as células-tronco possuem a enzima telomerase, que sintetiza telômeros. A manutenção da estabilidade dos telômeros é necessária para que estas células escapem da senescência replicativa e proliferem indefinidamente (SHAY, 2016). O encurtamento dos telômeros é considerado uma espécie de "relógio biológico" que sinaliza a senescência replicativa e o envelhecimento. O DNA telomérico é particularmente sensível ao estresse oxidativo. Além de causar dano oxidativo ao DNA telomérico, as EROs interferem com a atividade telomerase, inibindo sua atividade enzimática de elongação dos telômeros (AHMED; LINGNER, 2018).

Embora os cromossomos carreguem as informações genéticas, o epigenoma é o responsável pelo uso funcional e pela estabilidade dessas valiosas informações. Os mecanismos moleculares da regulação epigenética envolvem alterações nos padrões de metilação do DNA, modificações pós-traducionais das histonas e ação de micro RNA não codificantes, que juntos orquestram o remodelamento da cromatina (VILLOTA-SALAZAR; MENDOZA-MENDOZA; GONZÁLEZPRIETO, 2016). Múltiplos sistemas enzimáticos asseguram a geração $\mathrm{e}$ manutenção de padrões epigenéticos, incluindo as DNA metiltransferases, proteínas modificadoras de histona (acetilases, desacetilases, metilases e desmetilases), além dos complexos proteicos dependentes de ATP implicados na remodelação da cromatina (LIU; YIP; ZHOU, 2012).

Estudos revelaram que o epigenoma sofre uma perda progressiva em sua configuração durante o envelhecimento, semelhante a outras estruturas biológicas intracelulares, resultando em profundas mudanças na arquitetura cromossômica, na integração genômica e nos padrões de expressão gênica (PAL; TYLER, 2016). As alterações epigenéticas influenciam significativamente $o$ processo de envelhecimento por diversos mecanismos: perda de heterocromatina; redução global de histonas; instabilidade genômica resultante do relaxamento da cromatina, devido à perda de heterocromatina ou perda de histonas durante $o$ envelhecimento; variantes de histonas e alterações nas modificações pós-translacionais; a metilação do DNA muda com o envelhecimento bem como a interrupção da função de RNA (ácido ribonucleico) não codificante (LÓPEZ-OTÍN et al., 2013). 


\section{0 papel do metabolismo}

O processo de envelhecimento envolve alterações metabólicas e endócrinas, como mudanças na composição corporal, resistência à insulina e declínios fisiológicos do hormônio do crescimento $(\mathrm{GH})$ e de seu mediador secundário, o fator de crescimento semelhante à insulina-1 (IGF-1), além dos hormônios esteroides sexuais. Vias de sensores de nutrientes são altamente conservadas entre as espécies e têm efeitos amplos na saúde, emergindo como importantes reguladores de mecanismos fundamentais do envelhecimento (LÓPEZ-OTÍN et al., 2013).

A restrição calórica é a intervenção mais robusta para prolongar a vida e retardar o surgimento de patologias associadas ao envelhecimento de mamíferos descrita até o momento (COLMAN et al., 2014). Durante o jejum, o fígado sintetiza corpos cetônicosa partir de ácidos graxos, como o $\beta$-hidroxibutirato (BHB), um metabólito essencial para transportar energia do fígado para os tecidos periféricos quando o suprimento de glicose é muito baixo para as necessidades energéticas do corpo. Além de substrato energético, o BHB tem importantes funções na sinalização celular através da interação direta com proteínas, por exemplo, o BHB inibe diretamente a atividade de histonas deacetilases, regulando a expressão gênica. As interações moleculares do BHB com diversas proteínas regulam importantes funções fisiológicas, como o tônus simpático, o metabolismo lipídico, a inibição do inflamassoma. Foi demonstrado que o BHB aumenta a longevidade de C. elegans, e os estudos de restrição calórica e jejum intermitente sugerem fortemente que o BHB possa ter o mesmo efeito em mamíferos (EDWARDS et al., 2014).

A restrição calórica tem efeitos fisiológicos amplos, desde níveis reduzidos de citocinas, da adiposidade, sinalização de insulina/IGF-1, níveis de hormônios tireoidianos e aumento da adiponectina (YE; KELLER, 2010). Com essas alterações, as células induzem a ativação da autofagia, os mecanismos de defesa ao estresse e as vias de sobrevivência, atenuando os mediadores pró-inflamatórios e o crescimento celular, trazendo inúmeros benefício para a saúde (GOLBIDI et al., 2017). Já a dieta hipercalórica reduz a vida útil e acelera o aparecimento de doenças como diabetes, síndrome metabólica, câncer e doenças neurodegenerativas, enquanto que a restrição calórica atrasa o envelhecimento em uma ampla variedade de organismos, de levedura a primatas (COHEN, et al., 2004; GRUBER, et al., 2015). Está bem descrita a associação da obesidade com inflamação sistêmica crônica, uma comorbidade muito comum e altamente relevante por piorar o prognóstico de diversas doenças (YE; KELLER, 2010)

Vários estudos tentaram entender como a ingestão e o metabolismo de alimentos são associados à expectativa de vida no nível molecular. As sirtuínas são desacetilases dependentes de nicotinamida adenina dinucleotídeo (NAD) que têm papel crucial na regulação de uma variedade de processos celulares associados ao metabolismo e sinalização 
redox (FINKEL, 2015; SATOH, STEIN, IMAI, 2011). O estresse oxidativo leve induz a expressão de SIRT1, afetando seus alvos (SANTOS; ESCANDE; DENICOLA, 2016). Um alvo crítico do SIRT1 é a proteína p53, um fator de transcrição envolvido em diversas vias de sinalização, como o ciclo celular, reparo do DNA, autofagia, apoptose e ativação de defesas antioxidantes, como a superóxido dismutase-2 e a glutationa peroxidase-1 (SANTOS, ESCANDE, DENICOLA, 2016; SATOH, STEIN, IMAI, 2011). NAD são coenzimas que regulam funções vitais como a bioenergética, a homeostase redox, o metabolismo celular, vias de apoptose e autofagia. NAD é substrato de enzimas como as sirtuínas, PARP e CD38. Estudos com diversos organismos mostraram que os níveis de NAD declinam com o envelhecimento, e que a suplementação com NAD ou seus precursores têm efeito de inibir fenótipos do envelhecimento e promover a longevidade em diferentes modelos (GILMOUR et al., 2020).

Outro sensor de nutrientes essencial é o alvo de mamíferos da rapamicina (mTOR). Estudos demonstraram que a inibição da via de sinalização PI3K/ $\mathrm{Akt} / \mathrm{mTOR}$ prolonga a vida útil de organismos saudáveis, de leveduras a mamíferos (LAMMING, 2014). A inibição genética da sinalização de mTOR pode prolongar a vida útil de uma ampla gama de organismos, incluindo vermes, moscas e camundongos (FINKEL, 2015). A proteína cinase ativada por adenosina monofosfato (AMPK) e o sistema de reciclagem dependente de lisossomos, conhe- cido como autofagia, são outros dois elos críticos entre nutrientes e longevidade. Quando há depleção dos estoques intracelulares de energia, a AMPK é ativada e regula vias metabólicas que aumentam o fornecimento de energia para as células e reduzem a demanda energética. Ativação de sirtuínas e de AMPK e a inibição de mTOR atuam de forma a regular positivamente a autofagia, aumentando a longevidade (FINKEL, 2015).

\section{Senescência e exaustão de células-tronco}

A senescência celular é o processo de parada proliferativa permanente em resposta a vários estressores e um contribuinte essencial para o envelhecimento e doenças relacionadas à idade. Os fenótipos do envelhecimento são derivados de um aumento na frequência de células senescentes. A senescência pode resultar da perda de telômeros (senescência replicativa) ou estresse celular (senescência celular). Por um lado, a senescência é um importante mecanismo de supressão de tumores; por outro lado, causa uma perda da capacidade de reparo tecidual devido à parada do ciclo celular (CHILDS et al., 2015). Além disso, as células senescentes produzem moléculas pró-inflamatórias e degradantes da matriz no que é conhecido como fenótipo secretório associado a senescência (SASP). O SASP é iniciado principalmente por cascatas inflamatórias mediadas principalmente

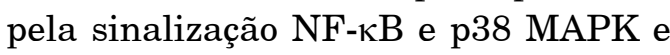
é mantido de forma autócrina (CHILDS 
et al., 2015). Uma das principais funções do SASP é recrutar o sistema imunológico para eliminar células senescentes e tumorais, mas o SASP também induz plasticidade celular e regeneração tecidual (RITSCHKA et al., 2017).

Uma das características mais marcantes do envelhecimento é o declínio da capacidade regenerativa. As células-tronco são responsáveis pelo desenvolvimento, renovação e regeneração tecidual, graças a sua capacidade de auto renovação e proliferação. Células tronco mesenquimais e hematopoiéticas são linhagens multipotentes derivadas de células tronco pluripotentes da medula óssea. Estas células perdem gradualmente seu potencial regenerativo com o avanço da idade (LIU, et al., 2020). A senescência das células-tronco é caracterizada in vitro pela perda da capacidade proliferativa e concomitante perda da capacidade de diferenciação. In vivo, as células tronco também são afetadas por falhas dos mecanismos homeostáticos (redes de autofagia, proteostase, reparo de danos ao DNA, disfunção mitocondrial etc) ou por condições que aceleram o envelhecimento do tecido, como a inflamação sistêmica de baixo grau associada à obesidade e algumas doenças crônicas. O envelhecimento altera não apenas o potencial replicativo, mas também a função das células tronco, como o perfil secretório e a imunomodulação (NERI; BORZİ, 2020).

EROs são importantes promotores do envelhecimento de células-tronco (CHEN et al., 2017). Sob condições de estresse leve, as células regulam a ex- pressão gênica relacionada à apoptose e aumentam a atividade de enzimas antioxidantes para atender às necessidades de defesas antioxidantes. As células possuem múltiplos sistemas antioxidantes, enzimáticos como peroxidases, catalases, superóxido dismutases e peroxiredoxinas, e solúveis como a glutationa, e outras moléculas com ação scavenger, que reagem com radicais livres e eliminam sua reatividade, protegendo organelas e macromoléculas do estresse oxidativo (FORMAN, 2016). Por outro lado, a produção excessiva de EROs gera um estresse oxidativo intenso e sustentado, que diminui a proliferação de células-tronco e promove envelhecimento prematuro, apoptose e eventualmente a formação de tumores (CHEN et al., 2017).

\section{Inflamação e imunosenescência}

O envelhecimento inevitavelmente leva à redução da função imunológica, deixando os idosos mais suscetíveis a infecções, menos capazes de responder aos desafios de patógenos e menos responsivos a vacinas preventivas. $\mathrm{O}$ impacto do envelhecimento sobre o sistema imunológico é conhecido como imunosenescência, e induz importantes alterações de sua função, tanto inata quanto adaptativa, levando a maior incidência de infecções, câncer, doenças autoimunes e outras morbidades (FÜLÖP, et al., 2016; PAWELEC, 2018).

A inflamação é um processo essencial para inúmeros fenômenos fisiológicos e patológicos. Dependendo do gatilho molecular, infeccioso ou não, a resposta 
inflamatória tem um objetivo fisiológico e diferentes consequências patológicas. A resposta inflamatória pode ser disparada por padrões moleculares associados a patógenos (PAMPs, de Pathogens Associated Molecular Patterns), ou por agentes não infecciosos, como estresse metabólico, lesão tecidual e liberação de padrões moleculares associados a danos (DAMPs, de Danger or Damage Associated Molecular Patterns), com o objetivo de induzir respostas de adaptação ao estresse, eliminar patógenos, promover a regeneração tecidual e restaurar a homeostase (MEDZHITOV, 2008).

Está bem estabelecida a correlação entre o estado pró-inflamatório sistêmico leve e doenças associadas ao envelhecimento, como diabetes e doenças cardiovasculares (FERRUCCI; FABBRI, 2018). Os níveis de interleucina 6 (IL-6) estão frequentemente acima da média em grande parte da população idosa (FRANCESCHI; CAMPISI, 2014). Essa condição inflamatória subclínica crônica está associada ao quadro de fragilidade e outras comorbidades, onde o idoso produz uma resposta pró-inflamatória exagerada a fatores exógenos, como estresses e infecções (D'AVILAet al., 2018; FERRUCCI; FABBRI, 2018).

Durante o envelhecimento, há um acúmulo natural de "lixo molecular", produzido fisiologicamente como consequência do metabolismo, danos aos tecidos e prejuízos na autofagia e na capacidade regenerativa (FRANCESCHI et al., 2017). A liberação de DAMPs, estimula continuamente a imunidade inata, funcionando como sinais de perigo endógenos. DNA nuclear e mitocondrial, ATP extracelular, excesso de glicose, ceramidas, catepsina B liberada a partir de lisossomos desestabilizados, proteínas amilóides agregadas, cristais de urato, lipoproteínas oxidadas são exemplos de DAMPs.

A produção de EROs induzida por mitocôndrias danificadas pode estimular sensores da resposta imune inata, que são plataformas multiproteicas intracelulares chamadas inflamassomas (FURMAN et al., 2017). A inibição da capacidade autofágica no envelhecimento aumenta o conteúdo de mitocôndrias disfuncionais e ativa os inflamassomas, em particular o receptor tipo Nod 3 (NLRP3) que desencadeia a maturação da interleucina-1 $\beta$ (IL-1 $\beta$ ), uma importante citocina pró-inflamatória (GOLDBERG; DIXIT, 2015; SALMINEN; KAARNIRANTA; KAUPPINEN, 2012). Esses mecanismos contribuem para o estado inflamatório crônico associado ao envelhecimento conhecido como Inflammaging (FRANCESCHI et al., 2017), uma espécie de imunosenescência da imunidade inata.

\section{Proteostase}

A proteostase compreende uma rede de diferentes vias altamente conservadas entre as espécies, um conjunto de mecanismos relacionados à síntese, conformação, tráfico, secreção e degradação de proteínas. Os principais agentes dessa rede incluem o sistema ubiquitina-proteassoma, as vias de autofagia, as chaperonas, proteínas de choque térmico 
e de resposta ao estresse, o retículo endoplasmático e os mecanismos que controlam o equilíbrio redox (VILCHEZ; SAEZ; DILLIN, 2014). O estresse exógeno ou endógeno causa a perda de conformação de proteínas (ou prejudica o dobramento adequado durante a síntese de proteínas) podendo causar uma agregação anormal de proteínas. Proteínas danificadas podem retomar sua conformação com $o$ auxílio de chaperonas, como a proteína de choque térmico de $70 \mathrm{kDa}$ (HSP70), ou ser direcionadas às rotas de degradação pela via ubiquitina-proteassoma ou pela via lisossomal e autofágica (BOLAND $e t$ al., 2018).

A autofagia é um mecanismo de restauração que controla a homeostase celular, facilitando a remoção de proteínas mal dobradas, bem como de organelas disfuncionais, mitocôndrias e retículo endoplasmático, para degradação no sistema lisossômico (SALMINEN; KAARNIRANTA; KAUPPINEN, 2012). Geralmente, a mitofagia elimina mitocôndrias não funcionais pelo sistema lisossômico, impedindo a produção excessiva de EROs e a ativação de inflamassomas. No entanto, durante o envelhecimento, a capacidade autofágica diminui e o aumento da produção de EROs e proteínas agregadas ativam inflamassomas que provocam inflamação em vários tecidos, inibem a autofagia e aceleram o processo de envelhecimento (SALMINEN; KAARNIRANTA; KAUPPINEN, 2012). Vacúolos autofágicos cheios de lipofuscina ou pigmentos de neuromelanina acumulam-se em tecidos envelhecidos. Estes pigmentos são compostos de macromoléculas altamente oxidadas (proteínas, lipídios e açúcares) com múltiplas origens metabólicas, derivadas principalmente da degradação das mitocôndrias ou outras organelas durante o envelhecimento. Estudos sugerem que estes agregados podem prejudicar a função celular dos tecidos envelhecidos e contribuir para declínio funcional do envelhecimento (SULZER et al., 2008).

O retículo endoplasmático é o principal local de síntese de proteínas na célula e um dos principais mecanismos para lidar com a agregação anormal de proteínas. Estímulos estressores, como hipóxia, privação de nutrientes, aumento da oxidação de proteínas e distúrbios da via secretora, podem levar a um acúmulo excessivo de proteínas agregadas no retículo, um processo denominado estresse do retículo endoplasmático (MARTÍNEZ et al., 2017). A eficiência dos sistemas de controle de qualidade diminui com a idade, juntamente com alterações na estrutura de proteínas devido a modificação oxidativa, mutações e má incorporação de aminoácidos durante a tradução. Uma redução na capacidade de manutenção da proteostase durante o envelhecimento pode aumentar 0 acúmulo de proteínas mal dobradas. O dobramento anormal de proteínas e formação de agregados proteicos tóxicos são importantes mecanismos da fisiopatologia de diversas doenças degenerativas associadas ao envelhecimento, como a doença de Alzheimer, doença de Parkinson, esclerose lateral amiotrófica, dentre outras (MARTÍNEZ et al., 2017). 


\section{Adaptação ao estresse}

Resistência ao estresse é o fenômeno pelo qual um estresse leve permite que células, tecidos ou organismos inteiros suportem níveis tóxicos de estresses subsequentes. Para lidar com as condições flutuantes de agentes estressores endógenos ou exógenos, como temperatura, $\mathrm{pH}$, estresse oxidativo, privação de nutrientes, hipóxia, osmolaridade e metais pesados, células e organismos passam por mudanças transitórias e reversíveis, adaptando-se e tornando-se mais resistente as alterações do meio, o que chamamos de homeostase adaptativa (LOMELI; BOTA; DAVIES, 2017).

À medida que a idade cronológica avança, o estresse celular e o dano tecidual aumentam. Enquanto o estresse agudo leva à toxicidade e morte celular, o estresse leve induz mecanismos homeostáticos de adaptação. Para lidar com todos os tipos de agentes estressores, as células respondem com ativação de fatores de transcrição e aumento dos sistemas de proteção (chaperonas, enzimas antioxidantes, hemeoxigenases, ferritina etc.), tornando-se mais resistentes a insultos subsequentes num fenômeno de pré-condicionamento (HAIGIS; YANKNER, 2010). Muitos estudos sugerem que um declínio na eficácia e integração das respostas ao estresse contribui para o envelhecimento e doenças relacionadas à idade (LOMELI; BOTA; DAVIES, 2017).

As principais fontes de radicais livres nas células são o metabolismo oxidativo, a cadeia respiratória das mi- tocôndrias e a família de enzimas NAD$\mathrm{PH}$ oxidase, produtoras de superóxido (SAHOO; MEIJLES; PAGANO, 2016). Quando a produção de espécies supera a capacidade da defesa antioxidante, causa danos oxidativos às proteínas, lipídios e ácidos nucléicos. Com o envelhecimento, há uma perda de equilíbrio entre a produção de ERO e as defesas antioxidantes, levando ao estresse oxidativo; as enzimas antioxidantes diminuem em tecidos envelhecidos (DRÖGE; SCHIPPER, 2007). O estresse oxidativo resulta em modificações oxidativas às biomoléculas e células, que a nível mitocondrial causa perda de competência bioenergética e, portanto, piora a função das células (DE LA FUENTE; MIQUEL, 2009). Disfunção mitocondrial, desdobramento e agregação de proteínas, dano ao DNA e outras biomoléculas, senescência e inflamação são consequências de desequilíbrios nas respostas ao estresse. $\mathrm{O}$ efeito primário das EROs é a ativação de respostas homeostáticas compensatórias ativando de mecanismos de transdução de sinal e sinalização celular. No entanto, acima de um certo limite, os níveis de EROs sobrecarregam os sistemas de defesa e, eventualmente, agravam os danos associados ao envelhecimento (HAIGIS; YANKNER, 2010).

\section{Considerações finais}

O envelhecimento é um fenômeno inexorável e altamente heterogêneo, que pode cursar com saúde (envelhecimento fisiológico) ou com doenças (envelhecimento patológico). Em organismos 
complexos multicelulares a interação entre fatores intrínsecos (genéticos), extrínsecos (ambientais) e estocásticos (danos aleatórios a biomoléculas vitais) determina a evolução do processo de envelhecimento. EROs são geradas dentro de sistemas biológicos e funcionam como moléculas sinalizadoras regulando diversas atividades celulares, como sobrevivência, respostas adaptativas, inflamação, etc. No entanto, a elevação de EROs e o estresse oxidativo estão amplamente associados ao aparecimento de injúria tecidual e progressão do envelhecimento.

O envelhecimento é o fator de risco mais significativo para o desenvolvimento de doenças degenerativas como câncer, diabetes, doenças cardiovasculares e neurodegenerativas. Assim, o aumento da longevidade será necessariamente acompanhado de uma maior incidências destas doenças. Portanto, torna-se cada vez mais necessária uma ampla compreensão dos mecanismos do envelhecimento, para propiciar o desenvolvimento de intervenções mais eficientes, voltadas não apenas para o aumento da longevidade, mas também para o aprimoramento da saúde e da qualidade de vida na terceira idade.

\section{Molecular mechanisms of aging: a literature review}

\section{Abstract}

Aging is a natural process characterized by a progressive decline in the physiological integrity and regenerative capacity of the body. In pathological aging, decline is accelerated and is often associated with a systemic pro-inflammatory status. Reactive species of oxygen and other free radicals are produced naturally in metabolism and during inflammation, but in excess they cause oxidative stress and tissue damage. With aging, the accumulation of oxidative changes alters the structure and function of biomolecules and cellular components such as membranes and organelles, making the organism globally more susceptible to stressors and pathogens. This review will focus on the contribution of oxidative stress to the different molecular mechanisms of aging. Aging is the main risk factor for the development of chronic-degenerative diseases. Therefore, the understanding of its molecular mechanisms will contribute to the development of new therapeutic strategies aimed at increasing the quality of life in aging.

Keywords: Aging. Oxidative stress. Inflammation. Molecular mechanism. Reactive oxygen species. 


\section{Referências}

AHMED, W.; LINGNER, J. Impact of oxidative stress on telomere biology. Differentiation, v. 99, p. 21-27, 2018. DOI: 10.1016/j. diff.2017.12.002.

BEARD, J. R.; OFFICER, A.; DE CARVALHO, I. A.; SADANA, R.; POT, A. M.; MICHEL, J. P.; LLOYD-SHERLOCK, P.; EPPING-JORDAN, J. E.; PEETERS, G. M. E. E.; MAHANANI, W. R.; THIYAGARAJAN, J. A.; CHATTERJI, S. The World report on ageing and health: A policy framework for healthy ageing. The Lancet, v. 387, n. 10033, p. 2145-2154, 2016. DOI: 10.1016/S01406736(15)00516-4.

BEST, B. P. Nuclear DN damage as a direct cause of aging. Rejuvenation Research, v. 12 , n. 3, p. 199-208, 2009. DOI: $10.1089 /$ rej.2009.0847.

BLASCO, M. A. Telomere length, stem cells and aging. Nature Chemical Biology, v. 3, n. 10 , p. $640-649,17$ Oct. 2007. DOI: $10.1038 /$ nchembio.2007.38.

BOLAND, B.; YU, W. H.; CORTI, O.; MOLLEREAU, B.; HENRIQUES, A.; BEZARD, E.; PASTORES, G. M.; RUBINSZTEIN, D. C.; NIXON, R. A.; DUCHEN, M. R.; MALLUCCI, G. R.; KROEMER, G.; LEVINE, B.; ESKELINEN, E. L.; MOCHEL, F.; SPEDDING, M.; LOUIS, C.; MARTIN, O. R.; MILLAN, M. J. Promoting the clearance of neurotoxic proteins in neurodegenerative disorders of aging. Nature Reviews Drug Discovery, v. 17 , n. 9 , p. $660-688$, 2018. DOI: 10.1038/nrd.2018.109.

BOVERIS, A.; OSHINO, N.; CHANCE, B. The cellular production of hydrogen peroxide. Biochemical Journal, v. 128, n. 3, p. 617-30, 1972. DOI: 10.1042/bj1280617.

BRATIC, A.; LARSSON, N. The role of mitochondria in aging. The Journal of Clinical Investigation, v. 123, n. 3, p. 951-957, 2013. DOI: 10.1172/JCI64125.Mitochondrial.
CHEN, F.; LIU, Y.; WONG, N. K.; XIAO, J.; SO, K. F. Oxidative Stress in Stem Cell Aging. Cell Transplantation, v. 26, n. 9, p. 1483-1495, 2017. DOI: 10.1177/0963689717735407.

CHILDS, B. G.; DURIK, M.; BAKER, D. J.; VAN DEURSEN, J. M. Cellular senescence in aging and age-related disease: From mechanisms to therapy. Nature Medicine, v. 21, n. 12, p. 1424-35, 2015. DOI: $10.1038 / \mathrm{nm} .4000$.

COHEN, H. Y.; MILLER, C.; BITTERMAN, K. J.; WALL, N. R.; HEKKING, B.; KESSLER, B.; HOWITZ, K. T.; GOROSPE, M.; DE CABO, R.; SINCLAIR, D. A. Calorie restriction promotes mammalian cell survival by inducing the SIRT1 deacetylase. Science, v. 305, n. 5682, p. 390-2, 2004. DOI: 10.1126/ science.1099196.

COLMAN, R. J.; BEASLEY, T. M.; KEMNITZ, J. W.; JOHNSON, S. C.; WEINDRUCH, R.; ANDERSON, R. M. Caloric restriction reduces age-related and all-cause mortality in rhesus monkeys. Nature Communications, v. 5, n. 3557, p. 1-5, 2014. DOI: $10.1038 /$ ncomms 4557 .

D'AVILA, J. C.; SIQUEIRA, L. D.; MAZERAUD, A.; AZEVEDO, E. P.; FOGUEL, D.; CASTRO-FARIA-NETO, H. C.; SHARSHAR, T.; CHRÉTIEN, F.; BOZZA, F. A. Age-related cognitive impairment is associated with long-term neuroinflammation and oxidative stress in a mouse model of episodic systemic inflammation. Journal of Neuroinflammation, v. 15, n. 1, p. 28, 30 Dec. 2018. DOI: 10.1186/s12974-018-1059-y.

DE LA FUENTE, M.; MIQUEL, J. An update of the oxidation-inflammation theory of aging: the involvement of the immune system in oxi-inflamm-aging. Current pharmaceutical design, v. 15, n. 26, p. 3003-26, 2009. DOI: $10.2174 / 138161209789058110$.

DRÖGE, W. Free Radicals in the Physiological Control of Cell Function. Physiological Reviews, v. 82, n. 1, p. 47-95, 2002. DOI: 10.1152/physrev.00018.2001. 
DRÖGE, W.; SCHIPPER, H. M. Oxidative stress and aberrant signaling in aging and cognitive decline. Aging Cell, v. 6, n. 3, p. 361-370, 2007. DOI: $10.1111 /$ j. 1474-9726.2007.00294.x.

EDWARDS, C.; CANFIELD, J.; COPES, N.; REHAN, M.; LIPPS, D.; BRADSHAW, P. C. D-beta-hydroxybutyrate extends lifespan in C. elegans. Aging, v. 6, n. 8, p. 621-644, 7 Aug. 2014. DOI: 10.18632/aging.100683.

FEDARKO, N. S. The Biology of Ageing and Frailty. Clinical Geriatric Medicine, v. 27 , n. 1, p. 27-37, 2011. DOI: 10.1016/j. cger.2020.08.006.

FERRARIS, D. V. Evolution of Poly(ADP-ribose) Polymerase-1 (PARP-1) Inhibitors. From Concept to Clinic. Journal of Medicinal Chemistry, v. 53, n. 12, p. 4561-4584, 24 Jun. 2010. DOI: $10.1021 / \mathrm{jm} 100012 \mathrm{~m}$.

FERRUCCI, L.; FABBRI, E. Inflammageing: chronic inflammation in ageing, cardiovascular disease, and frailty. Nature Reviews Cardiology, v. 15, n. 9, p. 505-522, 2018. DOI: 10.1038/s41569-018-0064-2.

FINKEL, T. The metabolic regulation of aging. Nature Medicine, v. 21, n. 12, p. 14161423, 8 Dec. 2015. DOI: 10.1038/nm.3998.

FORMAN, H. J. Redox signaling: An evolution from free radicals to aging. Free Radical Biology and Medicine, v. 97, p. 398-407, Aug. 2016. DOI: 10.1016/j.freeradbiomed.2016.07.003.

FRANCESCHI, C.; CAMPISI, J. Chronic inflammation (Inflammaging) and its potential contribution to age-associated diseases. Journals of Gerontology - Series A Biological Sciences and Medical Sciences, v. 69, p. S4S9, 2014. DOI: 10.1093/gerona/glu057.

FRANCESCHI, C.; GARAGNANI, P.; VITALE, G.; CAPRI, M.; SALVIOLI, S. Inflammaging and 'Garb-aging.' Trends in Endocrinology and Metabolism, v. 28, n. 3, p. 199-212, 2017. DOI: 10.1016/j.tem.2016.09.005.
FÜLÖP, T.; DUPUIS, G.; WITKOWSKI, J. M.; LARBI, A. The role of immunosenescence in the development of age-related diseases. Revista de Investigacion Clinica, v. 68, n. 2, p. 84-91, 2016. DOI: 10.1155/2018/6039171.

FURMAN, D.; CHANG, J.; LARTIGUE, L.; BOLEN, C. R.; HADDAD, F.; GAUDILLIERE, B.; GANIO, E. A.; FRAGIADAKIS, G. K.; SPITZER, M. H.; DOUCHET, I.; DABURON, S.; MOREAU, J.-F.; NOLAN, G. P.; BLANCO, P.; DÉCHANET-MERVILLE, J.; DEKKER, C. L.; JOJIC, V.; KUO, C. J.; DAVIS, M. M.; FAUSTIN, B. Expression of specific inflammasome gene modules stratifies older individuals into two extreme clinical and immunological states. Nature Medicine, v. 23, n. 2, p. 174-184, 2017. DOI: 10.1038/nm.4267.

GILMOUR, B. C.; GUDMUNDSRUD, R.; FRANK, J.; HOV, A.; LAUTRUP, S.; AMAN, Y.; RØSJØ, H.; BRENNER, C.; ZIEGLER, M.; TYSNES, O.-B.; TZOULIS, C.; OMLAND, T.; SØRAAS, A.; HOLMØY, T.; BERGERSEN, L. H.; STORM-MATHISEN, J.; NILSEN, H.; FANG, E. F. Targeting NAD+ in translational research to relieve diseases and conditions of metabolic stress and ageing. Mechanisms of Ageing and Development, v. 186, p. 111208, Mar. 2020. DOI: 10.1016/j.mad.2020.111208.

GOLBIDI, S.; DAIBER, A.; KORAC, B.; LI, H.; ESSOP, M. F.; LAHER, I. Health Benefits of Fasting and Caloric Restriction. Current Diabetes Reports, v. 17, n. 12, p. 123, 23 Dec. 2017. DOI: 10.1007/s11892-017-0951-7.

GOLDBERG, E. L.; DIXIT, V. D. Drivers of age-related inflammation and strategies for healthspan extension. Immunological Reviews, v. 265, n. 1, p. 63-74, 2015. DOI: 10.1111/imr.12295.

GRUBER, J.; CHEN, C.-B.; FONG, S.; NG, L. F.; TEO, E.; HALLIWELL, B. Caenorhabditis elegans : What We Can and Cannot Learn from Aging Worms. Antioxidants \& Redox Signaling, v. 23, n. 3, p. 256-79, 2015. DOI: 10.1089/ars.2014.6210. 
GRUBER, J.; HALLIWELL, B. Approaches for extending human healthspan: from antioxidants to healthspan pharmacology. Essays in Biochemistry, v. 61, n. 3, p. 389-399, 11 Jul. 2017. DOI: 10.1042/EBC20160091.

HAIGIS, M. C.; YANKNER, B. A. The Aging Stress Response. Molecular Cell, v. 40, n. 2, p. 333-44, 2010. DOI: 10.1016/j. molcel.2010.10.002.

HALLIWELL, B. Role of Free Radicals in the Neurodegenerative Diseases. Drugs \& Aging, v. 18, n. 9, p. 685-716, 2001. DOI: 10.2165/00002512-200118090-00004.

HALLIWELL, B.; GUTTERIDGE, J. M. C. Free Radicals in Biology and Medicine. Fifth Edit. Oxford: University Press, 2015. DOI: 10.1093/acprof:oso/9780198717478.001.0001.

KEENAN, C. R.; ALLAN, R. S. Epigenomic drivers of immune dysfunction in aging. Aging Cell, v. 18, n. 1, p. e12878, Feb. 2019. DOI: $10.1111 /$ acel.12878.

KENNEDY, B. K.; BERGER, S. L.; BRUNET, A.; CAMPISI, J.; CUERVO, A. M.; EPEL, E. S.; FRANCESCHI, C.; LITHGOW, G. J.; MORIMOTO, R. I.; PESSIN, J. E.; RANDO, T. A.; RICHARDSON, A.; SCHADT, E. E.; WYSS-CORAY, T.; SIERRA, F. Geroscience: Linking aging to chronic disease. Cell, v. 159, n. 4, p. 709-713, 2014. DOI: 10.1016/j. cell.2014.10.039.

LAMMING, D. W. Diminished mTOR signaling: a common mode of action for endocrine longevity factors. SpringerPlus, v. 3, n. 735, p. 1-11, 2014. DOI: 10.1186/2193-1801-3-735.

LIGUORI, I.; RUSSO, G.; CURCIO, F.; BULLI, G.; ARAN, L.; DELLA-MORTE, D.; GARGIULO, G.; TESTA, G.; CACCIATORE, F.; BONADUCE, D.; ABETE, P. Oxidative stress, aging, and diseases. Clinical Interventions in Aging, v. 13, p. 757-772, 2018. DOI: 10.2147/CIA.S158513.

LIU, B.; K.H YIP, R.; ZHOU, Z. Chromatin Remodeling, DNA Damage Repair and Aging. Current Genomics, v. 13, n. 7 , p. $533-547,1$ Sep. 2012 . DOI 10.2174/138920212803251373.

LIU, J.; DING, Y.; LIU, Z.; LIANG, X. Senescence in Mesenchymal Stem Cells: Functional Alterations, Molecular Mechanisms, and Rejuvenation Strategies. Frontiers in Cell and Developmental Biology, v. 8, p. 258, 5 May 2020. DOI: 10.3389/fcell.2020.00258.

LOMELI, N.; BOTA, D. A.; DAVIES, K. J. A. Diminished stress resistance and defective adaptive homeostasis in age-related diseases. Clinical Science, v. 131, n. 21, p. 2573-2599, 2017. DOI:10.1042/CS20160982.

LÓPEZ-OTÍN, C.; BLASCO, M. A.; PARTRIDGE, L.; SERRANO, M.; KROEMER, G. The hallmarks of aging. Cell, v. 153, n. 6 , p. 1194-1217, 2013. DOI: $10.1016 /$ j. cell.2013.05.039.

MANGERICH, A.; BÜRKLE, A. Pleiotropic Cellular Functions of PARP1 in Longevity and Aging: Genome Maintenance Meets Inflammation. Oxidative Medicine and Cellular Longevity, v. 2012, p. 1-19, 2012. DOI: 10.1155/2012/321653.

MARTÍNEZ, G.; DURAN-ANIOTZ, C.; CABRAL-MIRANDA, F.; VIVAR, J. P.; HETZ, C. Endoplasmic reticulum proteostasis impairment in aging. Aging Cell, v. 16, n. 4, p. 615-623, 2017. DOI: 10.1111/acel.12599.

MECOCCI, P.; MACGARVEY, U.; KAUFMAN, A. E.; KOONTZ, D.; SHOFFNER, J. M.; WALLACE, D. C.; BEAL, M. F. Oxidative damage to mitochondrial DNA shows marked age-dependent increases in human brain. Annals of Neurology, v. 34, n. 4, p. 609-16, 1993. DOI: $10.1002 /$ ana.410340416.

MEDZHITOV, R. Origin and physiological roles of inflammation. Nature, v. 545, n. 7203, p. 428-35, 2008. DOI: 10.1038/nature07201.

MULLER, F. L.; LUSTGARTEN, M. S.; JANG, Y.; RICHARDSON, A.; VAN REMMEN, H. Trends in oxidative aging theories. Free Radical Biology and Medicine, v. 43, n. 4, p. 477-503, 2007. DOI: 10.1016/j.freeradbiomed.2007.03.034. 
NERI, S.; BORZÌ, R. M. Molecular Mechanisms Contributing to Mesenchymal Stromal Cell Aging. Biomolecules, v. 10, n. 2, p. 340, 21 Feb. 2020. DOI: 10.3390/biom10020340.

PAL, S.; TYLER, J. K. Epigenetics and aging. Science Advances, v. 2, n. 7, p. e1600584, 2016. DOI: $10.1126 /$ sciadv.1600584.

PAUL, A.; BELTON, A.; NAG, S.; MARTIN, I.; GROTEWIEL, M. S.; DUTTAROY, A. Reduced mitochondrial SOD displays mortality characteristics reminiscent of natural aging. Mechanisms of Ageing and Development, v. 128 , n. $11-12$, p. 706-716, 2007. DOI: 10.1016/j.mad.2007.10.013.

PAWELEC, G. Age and immunity: What is "immunosenescence"? Experimental Gerontology, v. 105 , p. 4-9, 2018. DOI: $10.1016 /$ j. exger.2017.10.024.

PINTO, M.; MORAES, C. T. Mechanisms linking mtDNA damage and aging. Free Radical Biology and Medicine, v. 85, p. 250-258, Aug. 2015. DOI: 10.1016/j.freeradbiomed.2015.05.005.

RAY CHAUDHURI, A.; NUSSENZWEIG, A. The multifaceted roles of PARP1 in DNA repair and chromatin remodelling. Nature Reviews Molecular Cell Biology, v. 18, p. 610-621 2017. DOI: 10.1038/nrm.2017.53.

RITSCHKA, B.; STORER, M.; MAS, A.; HEINZMANN, F.; ORTELLS, M. C.; MORTON, J. P.; SANSOM, O. J.; ZENDER, L.; KEYES, W. M. The senescence-associated secretory phenotype induces cellular plasticity and tissue regeneration. Genes \& Development, v. 31, n. 2, p. 172-183, 15 Jan. 2017. DOI: 10.1101/gad.290635.116.

SACHA, J.; SACHA, M.; SOBOŃ, J.; BORYSIUK, Z.; FEUSETTE, P. Is It Time to Begin a Public Campaign Concerning Frailty and Pre-frailty? A Review Article. Frontiers in Physiology, v. 8, p. 484, 11 Jul. 2017. DOI: 10.3389/fphys.2017.00484.

SAHOO, S.; MEIJLES, D. N.; PAGANO, P. J. NADPH oxidases: key modulators in aging and age-related cardiovascular diseases?
Clinical Science, v. 130, n. 5, p. 317-35, 2016. DOI: $10.1042 / \operatorname{cs} 20150087$.

SALMINEN, A.; KAARNIRANTA, K.; KAUPPINEN, A. Inflammaging: Disturbed interplay between autophagy and inflammasomes. Aging, v. 4, n. 3, p. 166-75, 2012. DOI: 10.18632/aging.100444.

SANTOS, L.; ESCANDE, C.; DENICOLA, A. Potential modulation of sirtuins by oxidative stress. Oxidative Medicine and Cellular Longevity, v. 2016, p. 9831825, 2016. DOI: $10.1155 / 2016 / 9831825$.

SATOH, A.; STEIN, L.; IMAI, S. The role of mammalian sirtuins in the regulation of metabolism, aging, and longevity. Handbook of Experimental Pharmacology, v. 206, p. 125-62, 2011. DOI: 10.1007/978-3-64221631-2_7.

SHAY, J. W. Role of Telomeres and Telomerase in Aging and Cancer. Cancer Discovery, v. 6 , n. 6 , p. 584-593, 1 Jun. 2016. DOI: 10.1158/2159-8290.CD-16-0062.

SIES, H.; JONES, D. P. Reactive oxygen species (ROS) as pleiotropic physiological signalling agents. Nature Reviews Molecular Cell Biology, v. 21, p. 363-383, 2020. DOI: 10.1038/s41580-020-0230-3.

SOHAL, R. S. The Rate of Living Theory: A Contemporary Interpretation. Insect Aging. Berlin, Heidelberg: Springer Berlin Heidelberg, p. 23-44, 1986. DOI: 10.1007/978-3642-70853-4_3.

SULZER, D.; MOSHAROV, E.; TALLOCZY, Z.; ZUCCA, F. A.; SIMON, J. D.; ZECCA, L. Neuronal pigmented autophagic vacuoles: Lipofuscin, neuromelanin, and ceroid as macroautophagic responses during aging and disease. Journal of Neurochemistry, v. 106 , n. 1 , p. $24-36,2008$. DOI: $10.1111 /$ j. 1471-4159.2008.05385.x.

THEUREY, P.; PIZZO, P. The Aging Mitochondria. Genes, v. 9, n. 1, p. 22, 9 Jan. 2018. DOI: 10.3390/genes9010022. 
VAN DE VEN, R. A. H.; SANTOS, D.; HAIGIS, M. C. Mitochondrial Sirtuins and Molecular Mechanisms of Aging. Trends in Molecular Medicine, v. 23, n. 4, p. 320-331, 2017. DOI: 10.1016/j.molmed.2017.02.005.

VILCHEZ, D.; SAEZ, I.; DILLIN, A. The role of protein clearance mechanisms in organismal ageing and age-related diseases. Nature Communications, v. 5, p. 5659, 2014. DOI: 10.1038/ncomms6659.

VILLOTA-SALAZAR, N. A.; MENDOZAMENDOZA, A.; GONZÁLEZ-PRIETO, J. M. Epigenetics: from the past to the present. Frontiers in Life Science, v. 9, n. 4, p. 347-370, 2016. DOI: 10.1080/21553769.2016.1249033.

WEI, Y.-H.; LU, C.-Y.; LEE, H.-C.; PANG, C.-Y.; MA, Y.-S. Oxidative Damage and Mutation to Mitochondrial DNA and Age-dependent Decline of Mitochondrial Respiratory Function. ANNALS NEW YORK ACADEMY OF SCIENCES, v. 854, p. 155-70, 1998. DOI: 10.1111/j.1749-6632.1998.tb09899.x.

WEINERT, B. T.; TIMIRAS, P. S. Invited Review: Theories of aging. Journal of Applied Physiology, v. 95, n. 4, p. 1706-1716, Oct. 2003. DOI: 10.1152/japplphysiol.00288.2003.

WORLD HEALTH ORGANIZATION. World report on ageing and health. WHO Press, 2015.

YE, J.; KELLER, J. N. Regulation of energy metabolism by inflammation: A feedback response in obesity and calorie restriction. Aging, v. 6, n. 6, p. 361-368, 2010. DOI: 10.18632/aging.100155. 